\title{
Inverter Pure Sinus sebagai Pengganti Genset Berbasis IoT
}

\author{
Erni Widarti*1, Ernes Cahyo Nugroho², Ratna Herawati ${ }^{3}$, \\ Muhamaad Naufal Ma'arif ${ }^{4}$ \\ ${ }^{1,2,4}$ Program Studi Sistem Komputer, STMIK AUB, Surakarta, Indonesia \\ ${ }^{3}$ Program Studi Teknik Komputer, STMIK AUB, Surakarta, Indonesia \\ e-mail: *1erni.widarti@stmik-aub.ac.id, 2ernes.cahyo@stmik-aub.ac.id, \\ ${ }^{3}$ ratna.herawati@stmik-aub.ac.id, ${ }^{4}$ naufalmaarif02@gmail.com
}

\begin{abstract}
Abstrak
Pada jaman yang sudah maju ini teknologi menjadi peranan penting bagi masyarakat dimana perkembagan teknologi tidak lepas oleh sumber daya listrik yang mengakibatkan pihak PLN menambah daya bagi setiap lingkungan. Akan tetapi banyak pihak yang belum bisa merasakan kehadiran listrik terutama di daerah-daerah terpencil dan ini sangat mengganggu dalam aktivitas masyarakat. Sebagai alternatif untuk pemasokan listrik, banyak masyarakat menggunakan genset agar tidak mengganggu aktifitas atau pekerjaan masyarakat. Mengantisipasi adanya kejadian terputusnya aliran listrik dan kerusakan pada genset maka dibuatlah Inverter Pure Sinus. Inverter Pure Sinus ini berfungsi sebagai listrik cadangan sebagai langkah penggunaan listrik secara berkala. Inverter Pure Sinus yang banyak dijumpai dipasaran tidak bekerja secara optimal dan tidak dapat bekerja secara otomatis. Maka dilakukanlah penelitian menggunakan metode System Infrastructure Development Life Cycle for Enterprise Computing Systems (SIDLC), dari penelitian tersebt untuk menjawab dan mencoba dipecahkan dengan dibuatnya rangkaian intranstruktur Inverter Pure Sinus yang dapat bekerja secara otomatis dengan menggunakan modul ESP 8266 dan dapat dibawa kemanapun untuk sumber daya listrik.
\end{abstract}

Kata kunci-Inverter Pure Sinus , ESP 8266, Genset

\begin{abstract}
In this advanced era, technology has become an important role for society where technological development cannot be separated from electrical resources which results in the PLN adding power to every environment. However, many parties have not been able to feel the presence of electricity, especially in remote areas and this is very disturbing in community activities. As an alternative to electricity supply, many people use generators so as not to interfere with community activities or work. Anticipating the occurrence of power outages and damage to the generator set, the Pure Sinus Inverter was made. This Pure Sinus inverter functions as backup electricity as a step to periodically use electricity. Pure Sinus inverters that are often found in the market do not work optimally and cannot work automatically. So a research was carried out using the System Infrastructure Development Life Cycle for Enterprise Computing Systems (SIDLC) method, from this research to answer and try to solve it by making a Pure Sinus Inverter intranstructure circuit that can work automatically using the ESP 8266 module and can be taken anywhere for resources. electricity.
\end{abstract}

Keywords-Pure Sinus Inverter, ESP 8266, Generator

Received November 11, 2021; Revised November 25, 2021; Accepted December 17, 2021 


\section{PENDAHULUAN}

Pada jaman yang sudah maju ini teknologi menjadi peranan penting bagi masyarakat dimana perkembagan teknologi tidak lepas oleh sumber daya listrik yang mengakibatkan pihak PLN menambah daya bagi setiap lingkungan. Akan tetapi belum semua pihak bisa merasakan kehadiran listrik terutama di daerah-daerah terpencil dan ini sangat mengganggu dalam aktivitas masyarakat.

Sebagai alternatif untuk pemasokan listrik, banyak masyarakat menggunakan genset agar tidak mengganggu aktifitas atau pekerjaan masyarakat. Permasalahannya disini adalah sering terjadi kerusakan pada baterai genset atau tegangan yang menurun sehingga genset tidak dapat bekerja secara maksimal.

Mengantisipasi adanya kejadian terputusnya aliran listrik dan kerusakan pada genset maka dibuatlah Inverter Pure Sinus. Inverter Pure Sinus ini berfungsi sebagai listrik cadangan sebagai langkah penggunaan listrik secara berkala. Inverter Pure Sinus yang banyak dijumpai dipasaran tidak bekerja secara optimal dan tidak dapat bekerja secara otomatis salah satu pemecahan masalah diatas ialah dengan memperbaharui Inverter Pure Sinus agar bekerja secara optimal dan menjadi otomatis dengan menggunakan modul ESP 8266. Melalui ESP 8266, tampilan Notifikasi dapat ditambahkan sebagai penampil informasi penggunaan Inverter Pure Sinus. Selain itu, sebagai sistem proteksi perangkat, Inverter Pure Sinus juga mampu untuk melakukan tindakan secara otomatis berupa penonaktifan perangkat jika listrik dari PLN sudah menyala kembali, dengan berfungsinya alat ini maka dampak yang ditimbulkan akibat listrik yang padam bisa diminimalisir.

Berkembangnya teknologi Inverter Pure Sinus, diharapkan mampu memberikan tegangan yang baik serta mampu memberikan arus yang cukup kepada beban, sehingga apabila terjadi pemadaman listrik secara tiba -tiba, peralatan elektronika tidak mudah rusak dan masih aktif selama beberapa saat. Sebagai contoh kasus bentuk usaha yang terkait langsung dengan PLN seperti budidaya ikan, fotocopy, penjual jamu, dll. Berdasarkan latar belakang yang telah diuraikan ini maka penulis mengambil judul penelitian "Inverter Pure Sinus sebagai Pengganti Genset Berbasis IoT".

\section{METODE PENELITIAN}

\subsection{Observasi}

Metode Pengumpulan data dilakukan melalui peninjauan langsung ke rumah yang akan diteliti. Yakni seberapa butuhkah besaran listrik yang diperlukan di suatu rumah agar pembangunan infrastuktur Inverter Pure Sinus tidak mengalami kendala.

\subsection{Wawancara}

Metode pengumpulan data yang dilakukan melalui wawancara dengan warga sekitar dengan pembahasan topik mengenai kebutuhan listrik yang akan diterapkan pada salah satu rumah warga yang digunakan untuk pemasok cadangan listrik.

\subsection{Studi Literatur}

Penulis mencari, membaca dan mempelajari referensi berupa jurnal yang berhubungan dengan penelitian yang dilakukan tentang Inverter Pure Sinus menggunakan Akumulator (Aki) berserta informasi tambahan mengenai sistem operasi yang ditanam didalamnya.

\subsection{Tahap-Tahap Penelitian}

Tahap - tahap penelitian yang digunakan mengacu pada skema yang ditulis oleh Jiang (2009) dalam membangun infrastuktur sistem komputer, paling tidak terdapat 5 tahap untuk itu, yakni:

a. Analysist

GO INFOTECH: JURNAL ILMIAH STMIK AUB Vol. 27, No. 2, Desember 2021: 177-184 
Pada tahapan ini dilakukan dengan menganalisa data berupa: berapa banyak listrik yang digunakan, besarnya tegangan, pemetaan alat yang digunakan. Hasil yang didapatkan dari analisa ini akan digunakan untuk melaksanakan langkah selanjutnya.

b. Design

Melalui pendekatan metode SIDLC tahapan desain dilakukan dengan menyesuaikan beberapa factor lingkungan alat, lokasi pengguna, perangkat, aplikasi, dan aktivitas yang dapat dilakukan pengguna dengan alat yang di bangun.

c. Testing

Pengujian dilakukan dengan membuat prototype. Aplikasi yang digunakan untuk pengujian ini adalah android studio. Termasuk pula pengujian utama seperti: beban litrik dan perangkat yang tersambung.

d. Implementation

Tahapan implementasi di lakukan dengan mengintegrasikan Inverter Pure Sinus yang telah ditanamkan aplikasi notifikasi ke meteran listrik di dalam rumah. Meteran listrik yang telah dibangun dengan Inverter Pure Sinus yang ada pada rumah akan dihubungkan dengan ESP 8266, agar pengguna dapat menerima notifikasi untuk melakukan tindakan menghidupkan cadangan listrik.

\section{e. Maintenance}

Beberapa masalah yang ditemukan seperti beban pada litrik yang kadang melonjak, dan pemakaian yang berkala dapat membuat masa daya tahan Aki berkurang. Semua permasalahan yang telah didapatkan selanjutnya akan di lakukan troubleshooting agar alat yang dibangun sesuai dengan yang diharapkan.

\subsection{Perancangan Alat}

Rancangan elektronika terdiri dari aki sebagai sarana pengganti baterai, inverter bekerja sebagai pengubah arus dari DC (Direct Current) ke AC (Alternating Current), Kit Smart Charger Auto On \& Off Sebagai otomatis pengisi aki,Trafo 5A sebagai pembatas pengisian pada daya kepada aki agar tidak overload, relay sebagai pemutus dan penghubung aliran listrik kepada inverter, ESP8266 sebagai sarana pengirim notifikasi. Semua komponen itu akan digabung menjadi suatu alat yang bekerja sebagai alternatif jika listrik PLN padam seperti pada Gambar 1.

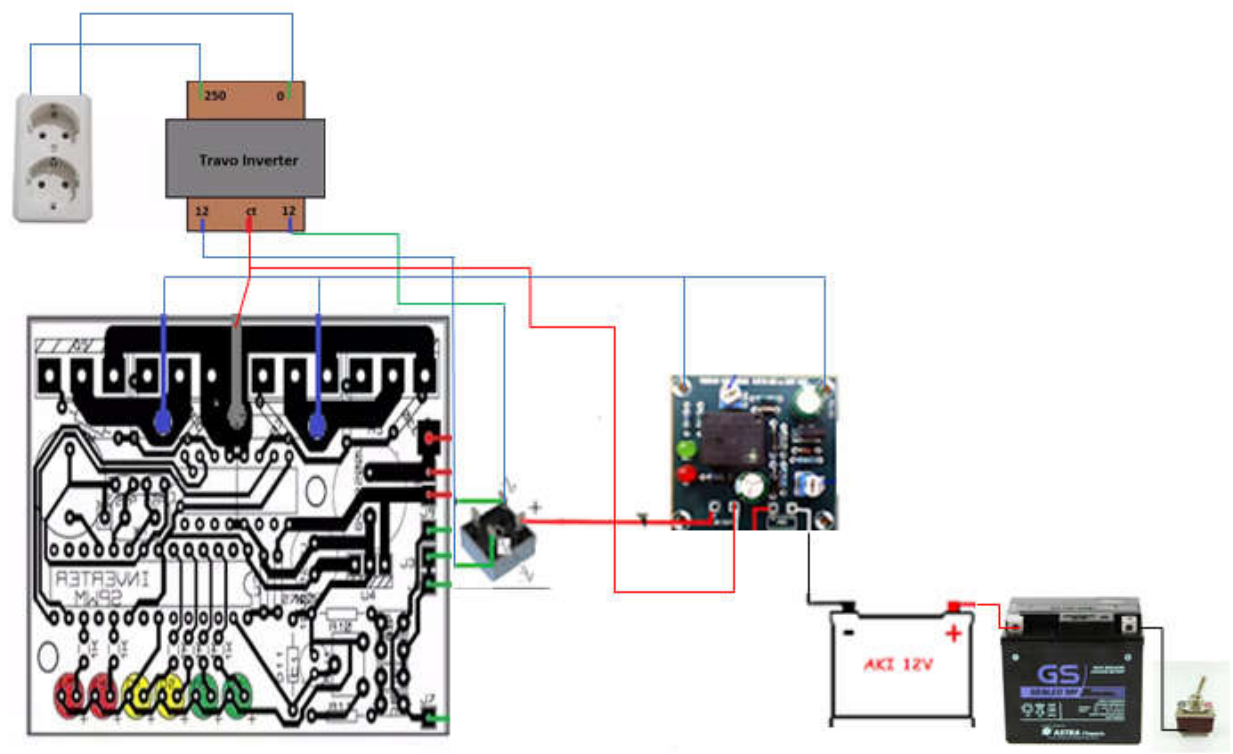

Gambar 1 Skema Perancangan 


\subsection{Flowchart inverter pure sinus}

Penjelasan alur kerja alat di jelaskan pada gambar 2 flowchart di bawah ini:

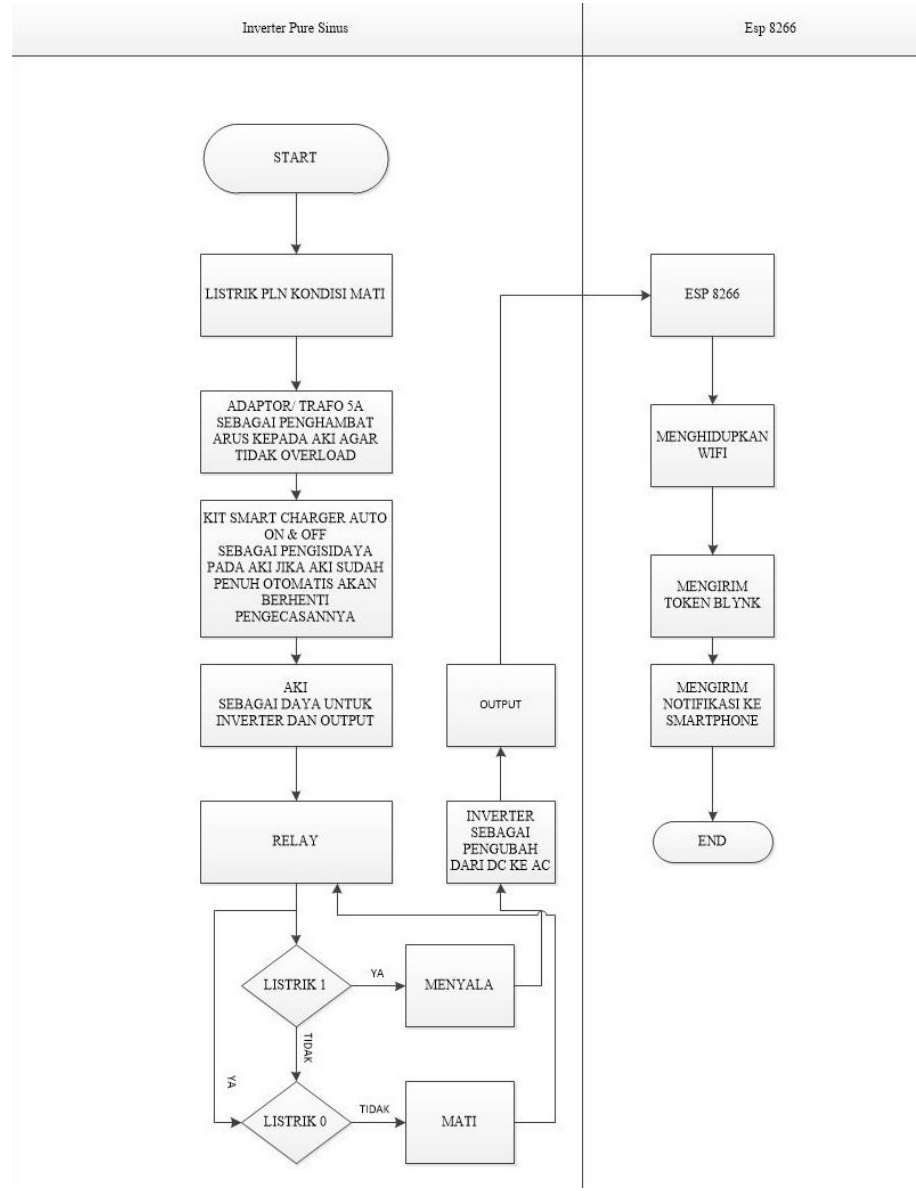

Gambar 2. Flowchart inverter pure sinus

Penjelasan Gambar 2 Flowchart Inverter Pure Sinus pengganti genset berbasis IoT dapat dijabarkan sebagai berikut:

a. START

Langkah pertama untuk alat bisa beroperasi jika kondisi listrik dari PLN dalam kondisi mati.

b. Adaptor/ Trafo $5 \mathrm{~A}$

Berfungsi sebagai pembatas pengisian daya agar tidak overload.

c. Kit smart charger auto cut on \& off

Setelah listrik benar-benar mati maka alat kit Smart Charger akan segera otomatis mematikan pengecasan pada aki .

d. Aki/Baterai

Setelah pengecasan berhenti maka aki akan menegluarkan daya arus listrik DC menuju ke inverter agar di konversi.

e. Relay

Setelah itu relay akan mengecek apakah listrik benar-benar sudah mati jika belum maka relay tidak akan mnyalurkan listrik ke inverter jika sudah mati maka arus akan menuju ke inverter.

f. Inverter

Setelah arus masuk inverter akan segera mengkonversi arus dc menjadi arus ac.

g. OUTPUT

Setelah semua selesai maka output akan segera bisa digunakan. 


\section{h. ESP8266}

Setelah output bisa di pakai maka ESP8266 akan segera mengirim menyala dan dapat mengirim Notifikasi ke pengguna.

i. END

Selesai alat sudah siap digunakan.

\section{HASIL DAN PEMBAHASAN}

\subsection{Implementasi}

Bagian ini berisi tentang hasil dari monitoring Inveter pure sinus sebagai pengganti genset berbasis IoT setelah dibuat. Pengujian alat dilakukan untuk mengetahui kinerja alat pada elektronik seberapa lama inverter pure sinus dapat bertahan dalam keadaaan listrik PLN mati sampai listrik bisa menyala kembali apakah sesuai dengan harapan dan dapat di implementasikan.

Hasil pengujian alat ini meliputi pengujian rangkaian ESP8266, Smart charger kit, Inverter, Trafo 5A, Relay, Saklar On Off dan Aki. Pengujian alat ini sudah dicoba dengan kegagalan 2 kali menggunakan baterai yang salah dan keberhasilan alat ini sudah diuji 3 kali dengan perangkat yang berbeda dan menunjkan daya tahan baterai yang berbeda.

Proses pembuatan Inverter pure sinus dengan menggunakan aki sebagai baterai yang di lengkapi dengan inverter sebagai perantara pengubah arus dan trafo $5 \mathrm{~A}$ sebagai penahan beban pengisian aki agar tidak overload. Smart charger kit sebagai otomatis untuk memutus aliran pengisian aki jika sudah penuh dan relay sebagai otomatis pemutus aliran listrik yang masuk dari aki ke inverter jika listrik PLN sudah menyala dan ESP8266 sebagai pengirim notifikasi jika alat sudah menyala dan bisa digunakan.

\subsection{Pengujian}

Pengujian alat berfungsi untuk menguji kinerja masing-masing komponen pada alat. Pengujian dilakukan dengan memasang alat dirumah dan digunakan jika terjadi mati pada listrik rumah. Apabila pada proses pengujian telah sesuai maka pengujian dihentikan dan dinyatakan telah berfungsi dengan baik, namun apabila pada proses pengujian terjadi kendala atau belum mencapai kondisi yang diinginkan maka dilakukan perbaikan dengan mengganti komponenkomponen atau pengecekan jika ada alat yang lepas.

Pengujian cara kerja alat bertujuan untuk mengetahui hasil dan proses cara kerja alat yang telah selesai dibuat berikut Gambar 3 proses pengujian alat.

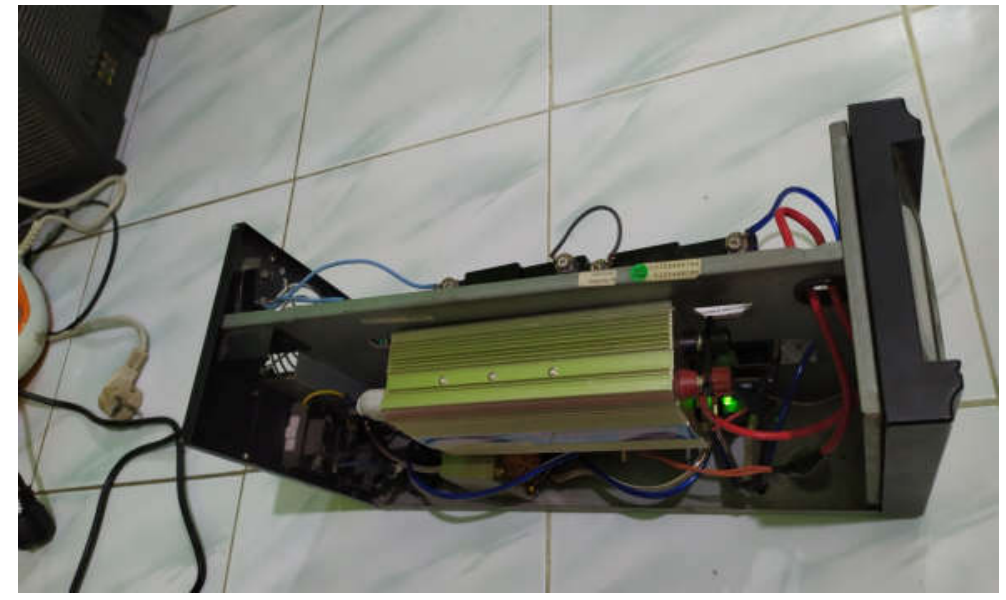

Gambar 3. Proses alat menyala

Gambar 3, pada proses ini alat siap digunakan di tandai oleh lampu indikator yang sudah menyala menjadi hijau tanpa harus menyeting segala macam langsng bisa digunakan untuk perabot rumah tangga. 


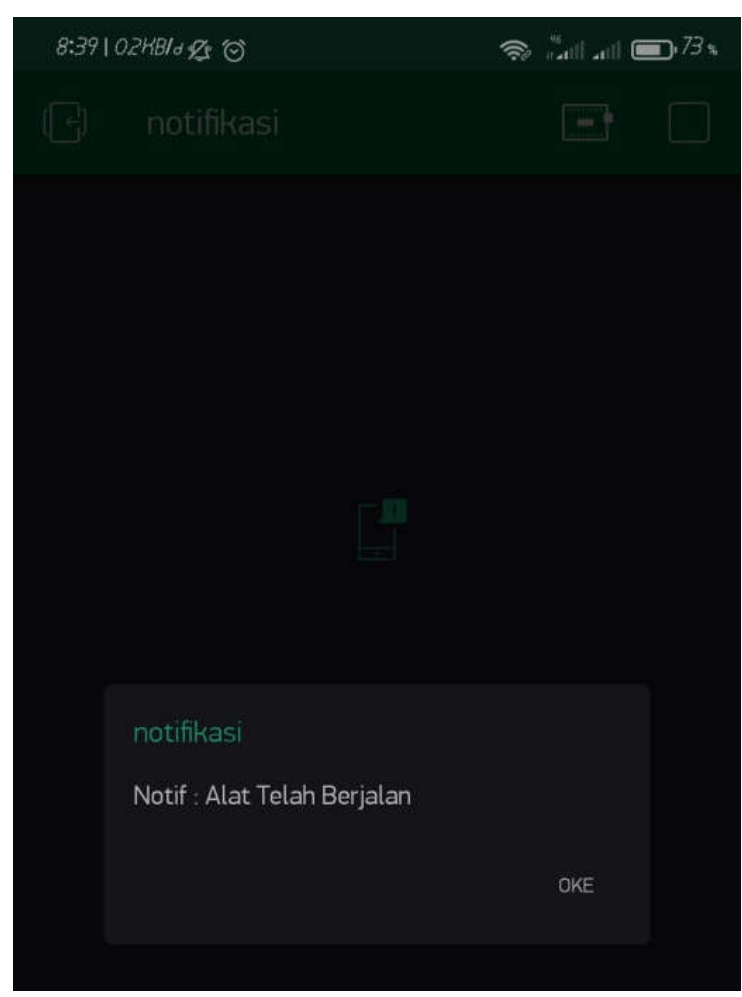

Gambar 4. Pesan Notifikasi

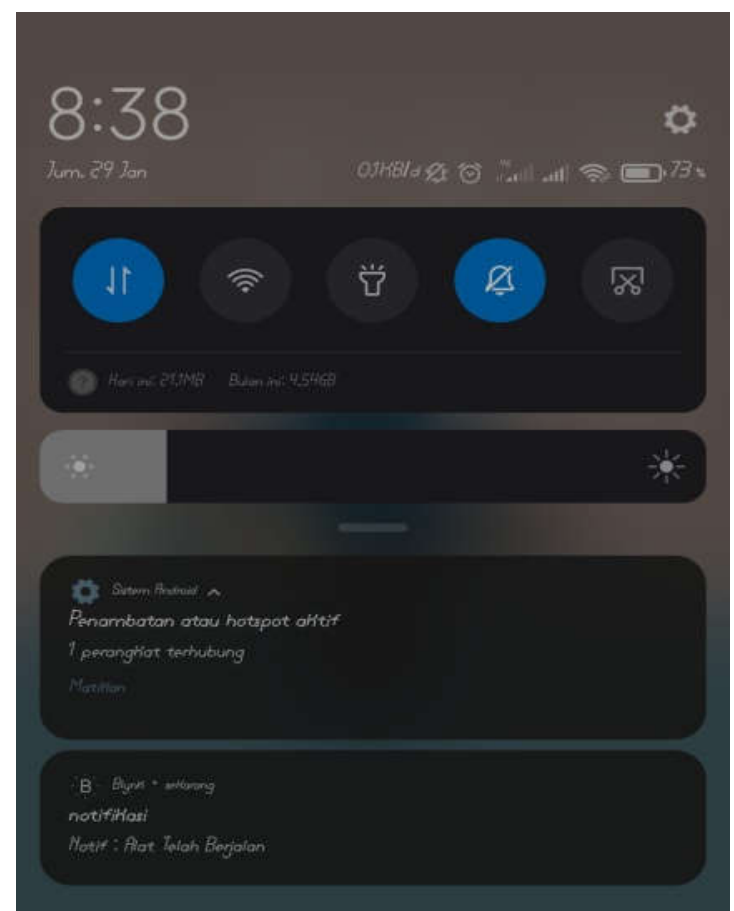

Gambar 5. Notifikasi pada Toolbar

Gambar 4 dan 5, pesan notifikasi memberitahu pada pengguna bahwa alat sudah siap untuk digunakan dan sedang berjalan. Berikutnya proses pengisian Aki/Baterai dapat dilihat pada Gambar 6. 


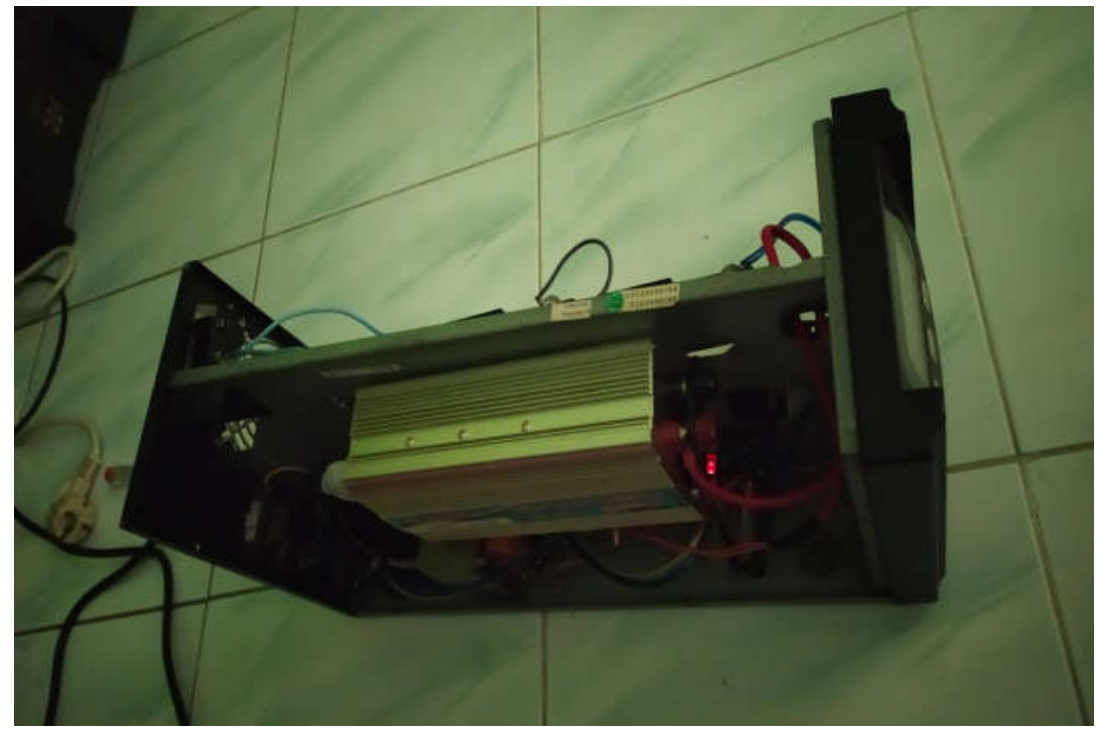

Gambar 6. Proses Pengisian Aki/baterai

Gambar 6, proses pengisian ini menandakan alat sedang melakukan pengisian aki/baterai ditadai dengan adanya lampu indicator merah yang menyala. Jika alatsudah siap untk di pakai kembali maka indikator akan berubah menjadi warna hijau yang artinya aki sudah terisi dengan penuh tanpa adanya overload dikarenakan oleh trafo $5 \mathrm{~A}$.

\subsection{Pembahasan}

Setelah dilakukan pengujian pada setiap blok rangkaian maka seluruh modul digabungkan menjadi sebuah alat. Kemudian dilakukan analisa keseluruhan alat secara utuh untuk mengetahui apakah alat telah bekerja sesuai dengan rencana awal. Berikut merupakan analisa dari alat yang telah sesuai dibuat:

a. Alat sudah berjalan dengan normal dan pengiriman notifikasi telah berjalan dengan baik dan alat bekerja tanpa ada kesalahan malfungsi.

b. Pada proses pengisian baterai juga tidak terjadi masalah tetapi ada kekurangannya yaitu sewaktu dimulai pengisian baterai alat sedikit mengeluarkan suara kipas tetapi juga itu yang menandakan bahwan proses pengisian berjalan dengan baik. notifikasi.

Berikut merupakan cara menggunakan alat Inverter Pure Sinus dan cara pengiriman

a. Langkah pertama hubungkan alat dengan listrik PLN bisa melalui Stop Kontak yang tersedia menggunakan kabel power.

b. Setelah itu pindah saklar yang terdapat pada alat dari OFF ke ON.

c. Kemudian alat mulai bekerja jika listrik PLN masih menyala alat memulai pengecasan terhadap aki/baterai, jika listrik PLN sudah mati total maka alat otomatis berjalan mengeluarkan aliran arus ke output.

d. Setelah alat berjalan maka ESP8266 memulai tugasnya mengirim notifikasi dengan jeda waktu 10-15 detik.

e. Kemudian notifikasi tersebut otomatis terkirim ke pengguna.

\section{KESIMPULAN}

Berdasarkan hasil penelitian yang telah dilakukan maka dapat ditarik kesimpulan bahwa alat ini telah bekerja dengan fungsinya, yaitu sebagai alat pengganti genset yang berbasis IoT. Pada hasil perancangan alat yang dibuat telah berhasil di rancang dan bekerja dengan sempurna 
dan bisa di terapkan pada masyarakat yang membutuhkan bantuan cadangan listrik. Pada proses pengiriman notifikasi sudah berjalan dengan lancar dan muncul di aplikasi blynk maupun notifikasi pada smartphone.

\section{SARAN}

Berikut saran yang diharapkan dalam pengembangan untuk kedepannya sebagai berikut alat ini belum bisa menampung daya yang besar, jadi jika memiliki daya yang besar maka alat ini akan bisa menghidupkan alat-alat elektronik dengan daya yang besar pula. Alat ini masih belum bisa menghidupkan alat yang memiliki tenaga dinamo, dikarenakan inverter yang digunakan berbeda dengan inverter yang bisa menghidupkan dinamo.

\section{DAFTAR PUSTAKA}

[1] Albaehaqi, F., Hong, T. S., Putro, T. Y., Syafar, A. M., Nusa, T., Sompie, S. R. U. A., Rumbayan, E. M., Hendrawati, T. D., Wicaksono, Y. D., Andika, E., \& ANDI SETIONO, S. (2018). Alat Pengukur dan Pensaklaran Penggunaan daya Listrik pada Ruangan berbasis IoT. Jurnal Ilmu Pengetahuan Dan Teknologi TELAAH, 1(1), 177.

[2] Anggoro, S. F. (2019). Powerbank. Powerbank untuk suplay daya beban pada rumahtinggal, 2.

[3] Fitrianda, M. I. (2013). Digital Digital Repository Repository Universitas Universitas Jember Jember Digital Digital Repository Repository Universitas Universitas Jember

[4] Muhammad Luqman, Eka Mandayatma, Sidik Nurcahyo. (2019). Eltek. Studi Komparasi Untuk Kerja Inverter 12V-DC ke 220V-AC yang ada di pasaran, 98.

[5] Rusman, S. (2014). Aki. Rancang Bangun Sistim Pengisian Baterai Otomatis Genset TIpe Rider di Kampus Kemaritiman Polnes Samarinda, 24.

[6] Saputra, A. J. (2019). UPS. Rancang Bangun Unintrerruptible Power Supply (UPS) Sebagai Back- up Berbasis Arduino, vii-1.

[7] Samsugi, Selamet, Ardiansyah, A., \& Kastutara, D. (2018). Arduino dan Modul Wifi ESP8266 sebagai Media Kendali Jarak Jauh dengan antarmuka Berbasis Android. Jurnal Teknoinfo, 12(1), 23. 